\title{
CONCLUSIONES DEL I ENCUENTRO NACIONAL DE TUTORES DE FORMACIÓN ESPECIALIZADA EN PSIQUIATRÍA Y PSICOLOGÍA CLÍNICA
}

El pasado 17 de noviembre de 1999 se celebró el I Encuentro Nacional de Tutores de Formación Especializada: MIR de Psiquiatría y PIR, en el marco de las XVI Jornadas Nacionales de la Asociación Española de Neuropsiquiatría, en Palma de Mallorca.

La jornada de trabajo tenía el objetivo de analizar, desde la práctica cotidiana, las confluencias y diferencias en el desarrollo real de los programas de especialización, dificultades y problemas, y la elaboración de conclusiones y propuesta de soluciones.

El encuentro reunió a unos 75 tutores MIR y PIR de todo el Estado que debatieron ampliamente sobre los programas teóricos, los circuitos de rotación, las comisiones de docencia y las comisiones asesoras, las tareas y figura de tutor y el sistema de evaluación. Al finalizar la jornada se pasó una pequeña encuesta para completar la información aportada en los debates.

Las principales conclusiones a las que se llegaron fueron:

\section{Los programas de formación} en Psiquiatría y Psicología Clínica $y$ circuitos de rotación

En este ámbito hay aspectos comunes a ambas Especialidades y específicos de cada una de ellas.

1. Se constata la existencia de importantes lagunas en diversas áreas de la formación teórica, tanto de MIR como de PIR, y la necesidad de articularlas en la formacion:
1.1. Psicoterapias. Independientemente del proyecto de creación de un área de capacitación específica, sería necesario definir un bloque teórico de técnicas psicoterapéuticas en la formación general.

1.2. Otras áreas también deficitarias son: rehabilitación, salud mental de niños y adolescentes, conductas adictivas, psicogeriatría y metodología de la investigación.

1.3. Una laguna específica del Programa MIR es la Psiquiatría Forense, y en el Programa PIR la Neuropsicología Clínica y la Psicología Forense.

2. Se considera necesario mantener en los programas teóricos los bloques comunes entre MIR y PIR, potenciando al mismo tiempo su especificidad, teniendo como referencia los programas de formación de cada Especialidad.

3. Para el correcto cumplimiento de los programas de formación, tiene que existir un equilibrio entre las actividades clínico-asistenciales y la docencia, evitando que los residentes sean utilizados como mano de obra. Un nivel de asistencia adecuado facilita la formación de los residentes. Es prioritario articular el programa teórico con la práctica clínico-asistencial, que se desarrolla en cada dispositivo específico; así como las particularidades del área sanitaria.

4. Existen importantes diferencias, tanto en los programas docentes como en la práctica asistencial, entre los hospitales monográficos y los hospitales generales, y entre éstos y los ser- 
vicios comunitarios. Esto supone una falta de homogeneidad en la formación de los residentes.

4.1. En ocasiones los MIR tienen una formación excesivamente hospitalaria perdiendo de vista la dimensión sociocomunitaria.

4.2. Los PIR, por el contrario, tienen dificultades para desarrollar sus rotaciones en el ámbito hospitalario, careciendo de la necesaria formación en las Unidades de Hospitalización y los programas de interconsulta.

5. Es necesario vigilar el cumplimiento de los objetivos de los programas de especialización, exigiendo la realización de auditorías en las Unidades Docentes acreditadas. En ocasiones se constata la ausencia de dispositivos y/o programas específicos en unidades acreditadas, lo que obliga a rotaciones externas, en el mejor de los casos.

6. Se señala la necesidad de establecer medidas que garanticen la buena formación del residente, como son: el diseño de indicadores asistenciales (por ejemplo, el tiempo de dedicación a cada paciente), la organización progresiva de las responsabilidades asistenciales, en función de las rotaciones por los dispositivos y programas y los años de residencia, el diseño de supervisiones regladas, la garantía de la disponibilidad y autonomía de los tutores, y la utilización adecuada del libro del residente.

7. Se señalan las dificultades para desarrollar un programa teórico homogéneo, dada la presencia simultánea de residentes de dos Especialidades y de distintos años. Una forma de solventar estos problemas sería la centralización de la formación teórica a nivel de las Comunidades Autónomas.
8. Se señala como un déficit importante la ausencia de investigaciones clínicas en salud mental y la inexistencia de ayudas.

9. En consonancia con lo que se está debatiendo en la Unión Europea, se plantea la necesidad de prolongar la duración de ambas Especialidades en un año, ya que se consideran insuficientes los 4 actuales en Psiquiatría y los 3 en Psicología Clínica.

La estructura docente, Comisiones de Docencia, Comisiones Asesoras y Tutorías

1. Se señala como problema generalizado el poco desarrollo de la estructura docente. Las Comisiones de Docencia tienen un funcionamiento burocratizado e irregular y las Comisiones Asesoras apenas se han desarrollado. Estas dificultades se derivan fundamentalmente de las características de ambas Especialidades, todavía consideradas como hospitalarias, pero que desarrollan gran parte de sus actividades fuera del ámbito hospitalario.

2. Es necesario el cumplimiento de la normativa legal existente (Orden Ministerial de 1995), aunque se ve conveniente trabajar en la línea de crear una Comisión de Docencia de área, específica de salud mental. Hay Comunidades donde ya se ha puesto en marcha esta iniciativa (Canarias, Cataluña, Navarra, Asturias).

3. La existencia de tutor extra e intrahospitalario induce a confusión y no responde a las necesidades y objetivos de la formación. En su lugar se propone un tutor general, responsable de la formación general, y tutores de rotación, responsables de los dispositivos específicos. Estos tutores deben 
ser de la misma Especialidad que el residente (psiquiatras o psicólogos).

4. El tutor debe tener un perfil específico todavía no suficientemente definido, conocimientos amplios de la especialidad, determinadas actitudes para el trabajo en equipo y suficiente autonomía. Es necesario diferenciar la figura del tutor de la del supervisor. El tutor ordena y sistematiza el conjunto de tareas de la formación, el supervisor se encarga de un área específica, en la cual debe estar acreditado, siendo indiferente en este sentido que sea psiquiatra o psicólogo. Se señala la importancia del binomio supervisor-tutor para engarzar lo teórico y lo práctico.

5. Se señala como un problema importante la desmotivación de los profesionales para asumir tareas de tutorización y supervisión, dada la falta de reconocimiento y acreditación para las tareas docentes y la sobrecarga asistencial. Es necesario conceder tiempo e incentivos (curriculares, económicos, etc.) al tutor.

6. Se constata la falta de homogeneidad y claridad en los nombramientos de los tutores; a este respecto se debería respetar la normativa vigente.

\section{El sistema de evaluación y el libro del residente}

1. La evaluación es un instrumento al servicio de la formación, que proporciona al residente información continuada sobre su posición, en relación con el conjunto de conocimientos y habilidades que ha de adquirir. Por lo tanto, constituye un aspecto central del proceso de aprendizaje.

2. Se considera que el examen final, como sistema de evaluación, es ineficaz para evaluar la capacitación adqui- rida, y se considera que la evaluación continuada que propone la Orden Ministerial de 1995 es más adecuada.

3. Sin embargo, el sistema de evaluación actual, que introduce una escala calificadora (suficiente, destacado y excelente), es arbitrario y por lo tanto injusto e ineficaz.

4. En su lugar se propone una evaluación cualitativa que persiga describir el perfil profesional individualizado logrado por el residente al concluir su formación.

5. La evaluación continuada solamente será posible cuando la figura del tutor tenga un reconocimiento oficial y sus funciones sean definidas y respetadas.

6. El libro del residente ocupa un lugar central en el proceso de formación y especialmente en la evaluación continuada, pero su función debe incluir la evaluación pormenorizada del entrenamiento asistencial y la adquisición de conocimientos del residente.

A tenor de las anteriores conclusiones, la Asociación Española de Neuropsiquiatría hace las siguientes recomendaciones:

1. En lo que respecta a los contenidos de la formación especializada, se debería completar con aquellos aspectos que la experiencia ha demostrado que son deficitarios, a saber: rehabilitación, conductas adictivas, psicogeriatría, metodología de investigación, psicología y psiquiatría del niño, psicología y psiquiatría forense, y neuropsicología. Por otro lado, se debería potenciar la actividad de las Comisiones de Docencia o, incluso, crearse comisiones específicas para salud mental, y potenciar y prestigiar, asimismo, la figura del tutor de formación, dotando de contenidos esta función. 
2. En lo que atañe a la evaluación de los conocimiento adquiridos durante la especialización, la AEN considera necesario garantizar la calidad de los mismos mediante la adopción de sistemas de evaluación continuada que se atengan a criterios homogéneos y fiables; en este aspecto el libro del residente ocupa un lugar principal. Aunque el actual libro común a todas las Especialidades es ineficaz para recoger las actividades específicas de nuestros Especialistas en formación, por lo que sería necesario elaborar uno nuevo.

3. Por último, es preciso potenciar la investigación en el campo de la salud mental mediante la ampliación del número y cuantía de las becas de investigación existentes, la creación de becas específicas para personal en formación, etc.

Asociación Española de Neuropsiquiatría (AEN) 